\title{
Rehabilitation of Discoloured and Malaligned Maxillary Anterior Teeth
}

1. Dr. Shruti S Potdukhe

Post Graduate Student, Department of Prosthodontics and Crown \& Bridge, MGM Dental College and Hospital, Navi Mumbai, India

\author{
2. Dr. Janani M Iyer \\ Reader, Department of Prosthodontics and Crown \& Bridge, \\ MGM Dental College and Hospital, \\ Navi Mumbai, India
}

\author{
3. Dr. Jyoti B Nadgere \\ Professor and Head of Department of Prosthodontics and Crown \& Bridge, \\ MGM Dental College and Hospital, \\ Navi Mumbai, India
}

\begin{abstract}
This article contains the management of discoloured teeth using conservative approach of intracoronal bleaching and gradation method of tooth preparation for reducing the tooth shade and restoration of the prepared teeth with fixed dental prosthesis.
\end{abstract}

In this article a case report of management of discolored and malaligned maxillary anterior teeth have been presented.

Keywords:- Bleaching, Ceramic, Gingival porcelain, Tooth Preparation, Discolouration.

\section{INTRODUCTION}

Discoloration of tooth can occur because of various reasons such as trauma, road traffic accidents, developmental diseases, congenital factors, fluorosis, thermal injury and many more. Discoloration can be intrinsic as well as extrinsic in nature. Any kind of discoloration results into poor appearance and ultimately poor psychological effect.

Esthetic is of prime importance for any individual despite of any age group. To enhance esthetic outcome of the worst scenario various approaches has to be included. Bleaching is a treatment modality involving an alternative chemical that alters the light absorbing and light reflecting nature of material structure, thereby increasing its perception of whiteness [1].

Gradation method of tooth preparation depends upon the amount or number of shade has to be changed for particular tooth. With more amount of reduction more the change in shade can be obtained.

In this article will discuss about intracoronal bleaching for non vital tooth, gradation method for reduction in tooth shade followed by smile designing for maxillary anteriors.

\section{CASE PRESENTATION}

\section{A. CASE HISTORY}

A 23 years old male patient reported to the Dept. of Prosthodontics with the chief c/o of poor esthetic due to discolored teeth in upper front region of jaw since 1 year. He is co-operative follows mixed diet no habits fair oral hygiene and had normal expectations. Past history revealed history of trauma to face 4 yrs back.

Past dental history revealed extraction with 25,15 years back and 46; 25-30 years back due to caries.

\section{B. Extraoral examination:}

Patient has square facial form, straight profile, no gross asymmetry, high smile line, adequate lip support and normal functioning of Temperomandibular Joint. Fig. 1.

C. Intraoral examination: Fig. 2.

Purplish discoloration seen with 11,21 and brown discoloration with 22 Root canal treatment done with $11,21,22$ Restoration seen with $16,17,26,27,28,36,37,38,48$ All metal crown with 47 Hypoplastic spot seen on 13,12,23.

D. Treatment Planning:

1. Intracoronal Bleaching with 11,21

2. Post and Core Build Up With 11,21,22

3. Smile analysis

Zirconia layered emax crown with 11,21,22 and

Lithium disilicate laminate with 12,13,23

4. Preparation type:

Radial shoulder margins for Full coverage crown and Chamfer margin for laminates

\section{E. Procedure:}

After the final treatment plan was decided the shade obtained with $13,12,23,22$ was A2 with 11,21 was $\mathrm{C} 4$. 
$2 \mathrm{~mm}$ of coronal gutta percha was removed from canal of 11,21. Placement of $2 \mathrm{~mm}$ of Glass Ionomer Cement was done into canal. Placement of mixture of Sodium perborate with hydrogen peroxide on labial surface. Fig.3. Intermediate restoration was done with Glass

Ionomer Cement [2]. After the recall of 3 weeks the shade for reduce to lower grade. According to Galip Gurel tooth preparation was done for laminates with 12, 13, 23 and for full coverage crown with 11, 21. Fig.4. Gingival retraction with $25 \%$ Aluminium chloride was done and final impression was made with addition silicone (Flexceed) technique [3]. Fig.5. To mask the colored of discolored tooth zirconia layered Emax crowns with 11,21 and lithium disilicate crown with 22 and laminates with 12,13,23 were fabricated. Addition of Gingival Porcelain was done with 21 for soft tissue defect. Final Cementation of zirconia crowns with 11, 21 done using resin cement. Final bonding of lithium disilicate crowns and laminates done with dual cure resin cement (Relyx). Fig.6. Resulted into a Happy and Smiling Patient. Fig.7.

\section{DISCUSSION}

Tooth discoloration is defined as any change in hue, color, translucency of tooth due to any causes [4]. Trauma to the tooth can result into the pulpal necrosis; degradation of haemoglobin into hemin, hematin, hematoiden and haemosidrin. Hydrogen sulphide produced by bacteria combines with hemoglobin \& gives dark colour to tooth and can cause purple discoloration [5]. Bleaching is one of the treatment modality for discolored tooth. Various bleaching agent can be used. In this case sodium perborate with 30 to $35 \%$ hydrogen peroxide was used effectively.

For laminate tooth preparation Galip Gurel technique including Aesthetic pre- Recontouring and Aesthetic PreEvaluative Temporaries method was used [6].

Principles of tooth preparation includes Graded Tooth Preparation which states that Greater the color change greater the amount of tooth reduction. For moderate color change moderate preparation is done known as Universal Preparation. For profound color change upto three shades deeper biplanar facial reduction is done [7] for 11, 21.

Depending upon vitality and discoloration of tooth zirconia layered Emax crowns were fabricated was 11 \& 21with addition of Gingival Porcelain to 21 and fabrication of lithium disilicate laminates with $12,13,23$ and lithium disilicate crown with 22 as they provide better esthetics.

\section{CONCLUSION}

Smiling face is always a requirement for a confident life. Better the smile better is the life. Non vital tooth with traumatic history always require an interdisciplinary approach including root canal treatment, Bleaching and prosthodontic approach for restoration of the prepared tooth. Thus combination of methods can be used to enhance the final outcome of the discolored and malaligned teeth.

\section{FIGURES}

Figure 1

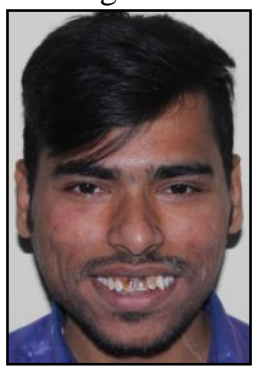

Fig.1 Pre Operative Extraoral Picture

Figure 2:

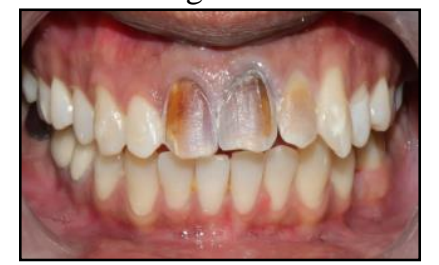

Fig. 2 Pre Operative Intraoral Picture

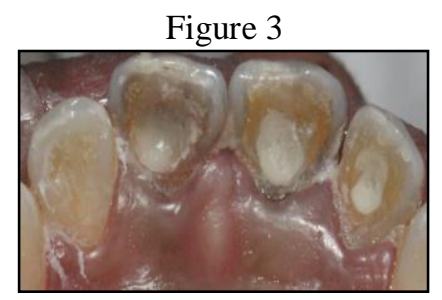

Fig.3 Intracoronal bleaching

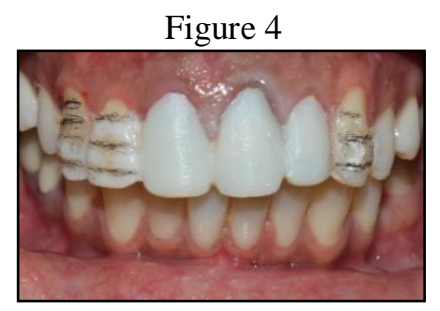

Fig. 4 Galip Gurel Technique

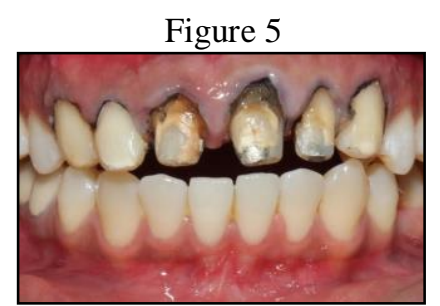

Fig.5 Tooth Preparation with Gingival Retraction

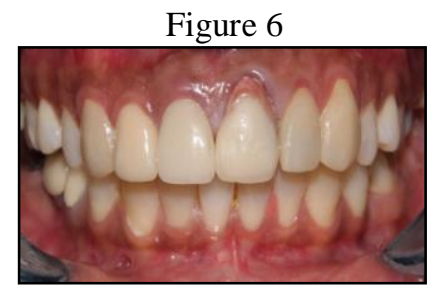

Fig.6 Final cementation of crowns and bonding of laminates 
Figure 7

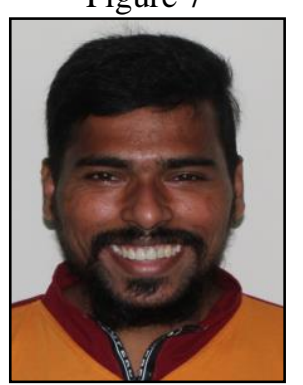

Fig. 7 Post Operative Extraoral Picture

\section{REFERENCES}

[1]. Arens D. The role of bleaching in esthetics. Dental Clinics of North America. 1989 Apr 1;33(2):319-36.

[2]. MacIsaac AM, Hoen CM. Intracoronal bleaching: concerns and considerations. Journal (Canadian Dental Association). 1994 Jan 1;60(1):57-64.

[3]. Nowakowska D, Saczko J, Kulbacka J, Choromanska A. Dynamic oxidoreductive potential of astringent retraction agents. Folia Biol (Praha). 2010 Jan 1;56(6):263-8.

[4]. Van der Burgt TP, Plasschaert AJ. Tooth discoloration induced by dental materials. Oral Surgery, Oral Medicine, Oral Pathology. 1985 Dec 1;60(6):666-9.

[5]. Kansal S, Jindal L, Garg K, Thakur K, Mehta S, Pachori H. Discoloration of Teeth: A Literature Review. International Journal of Health and Clinical Research. 2020 May 31;3(2):58-62.

[6]. Predictable and precise tooth preparation techniques for porcelain laminate veneersI $\mathrm{n}$ complex cases. Galip gürel. International dentistry sa vol. 9, no. 1

[7]. Peumans M, Van Meerbeek B, Lambrechts P, Vanherle G. Porcelain veneers: a review of the literature. Journal of dentistry. 2000 Mar 1;28(3):163-77. 